\title{
Interleukin- 17 and type 17 helper T cells in cancer management and research
}

\author{
This article was published in the following Dove Press journal: \\ ImmunoTargets and Therapy \\ 10 March 2014 \\ Number of times this article has been viewed
}

\author{
Nicolas J Llosa' \\ Abby L Geis ${ }^{2}$ \\ Erik Thiele Orberg ${ }^{2}$ \\ Franck Housseau ${ }^{2}$ \\ 'Department of Pediatric Oncology, \\ ${ }^{2}$ Department of Oncology, Sidney \\ Kimmel Comprehensive Cancer \\ Center, Johns Hopkins University, \\ Baltimore, MD, USA
}

\begin{abstract}
Since their recent discovery, T helper 17 (Th17) cells have been frequently detected in the tumor microenvironment of many malignancies, but their clinical implications remain largely unknown. Interleukin-17 (IL-17) detection is commonly related with poor outcomes in colorectal cancers, yet its presence is associated with antitumor responses in ovarian carcinomas. Numerous experimental models illustrate the divergent roles of Th17 cells in tumor immunity, which appears to be mainly dependent on the tumor context (type, location, and stage of cancer). It is recognized that IL-17 is produced by a variety of cell types and that Th17 cells are endowed with a unique functional plasticity. Therefore, when trying to elucidate potential immune biomarkers and immunotargets, it is extremely important to make a clear dissociation between strategies targeting Th17 versus its hallmark cytokine, IL-17. In this review, we will summarize the data regarding the detection of IL-17 and Th17 in human cancers, consider the experimental evidence on their respective roles in antitumor activity, and discuss the potential of IL-17 as an immune target for therapeutic interventions.
\end{abstract}

Keywords: biomarkers, inflammation, tumor microenvironment

\section{Immunotherapy in cancer}

"Evading immune destruction" has recently been introduced by Hanahan and Weinberg in the revised definition of "hallmarks of cancer," illustrating the remarkable progress made in the last decade to describe the role of inflammation in promoting cancer development. ${ }^{1}$ It is well established that, during its progression, cancer 1) triggers an immune response, then 2) co-opts the immune cells and mediators for tumor growth and survival, and 3) can evade immune-mediated killing. The concept of cancer vaccine, a T-cell-based immunotherapy approach meant to eradicate cancer cells while establishing long lasting antitumor memory, has its roots in the demonstration that nascent cancer cells and their cortege of associated neoantigens trigger endogenous immune responses. Tumor-infiltrating cluster of differentiation (CD) $8^{+}$cytotoxic $\mathrm{T}$ lymphocytes (CTL) that recognize and eliminate cancer cells in an antigen specific manner are usually associated with antitumor immune response. ${ }^{2,3}$ However, even though numerous Phase I/II clinical trials demonstrated the proof of principle that antitumor immune responses can be efficiently induced, the paucity of objective clinical responses and data showing a benefit to patients forced the reconsideration of immunotherapeutic approaches. ${ }^{4}$ One major obstacle for successful T-cell-based immunotherapies is the ability of cancer to escape the immune response by either suppressing the expression of tumor-associated antigens (loss of antigen, downregulation of major histocompatibility complex [MHC]), or subverting the tumor-associated inflammation via the recruitment of suppressive cells, like 
regulatory T cells (Treg) or immature myeloid cells, leading to inhibition of immune effectors such as CTL and natural killer (NK) cells. ${ }^{5,6}$ Molecular identification of these protumoral mediators (including interleukin [IL]-6, IL-23, and vascular endothelial growth factor [VEGF]) and immunosuppressive pathways (including signal transducer and activator of transcription [STAT]3, immune checkpoints such as programmed cell death protein 1 [PD-1] or cytotoxic T-lymphocyte antigen 4 [CTLA-4]) have led to the development of immune targets for cancer therapy as recently successfully demonstrated in clinical trials. ${ }^{7,8}$ Ipilimumab, a monoclonal antibody (mAb) which blocks the immunomodulatory receptor CTLA-4 was approved by the Food and Drug Administration for the treatment of metastatic melanoma in $2011 .{ }^{9}$ Similarly, successful clinical studies using the blockade of the PD-1/programmed cell death 1 ligand 1 (PD-L1) immunomodulatory pathway predict the rapid approval of these drugs for the treatment of advanced cancers such as refractory melanoma, renal carcinoma, and lung cancer. ${ }^{10}$ This recent breakthrough in cancer immunotherapy justifies taking a closer look at biomarkers that can predict clinical outcome and response to therapies. For instance, the expression of PD-L1, an immunosuppressor ligand long considered to be a negative prognostic marker because it blocks the action of activated $\mathrm{PD} 1^{+} \mathrm{CTL}$, was upregulated on melanoma cells in response to interferon gamma (IFN- $\gamma$ ) production. ${ }^{11}$ In this study, PD-L1 became a biomarker of endogenous antitumor immune activity, predicting a positive clinical response to the PD-1 blockade.

These findings and others proved that local immune reactions influence the clinical outcome in human tumors and their response to treatment. ${ }^{12}$ Whereas the density of $\mathrm{CD} 8^{+} \mathrm{CTL}$ and $\mathrm{CD}_{45 \mathrm{RO}^{+}}$memory $\mathrm{T}$ cells in tumor is correlated with better prognosis in a variety of cancers, the prognostic value of $\mathrm{CD}^{+}$cells infiltration, including Treg and IL-17A (IL-17) producing T helper 17 (Th17) cells, remains largely unclear. In recent times, IL-17 and Th17 detection have gained a lot of attention in the field and have triggered a lot of controversy in terms of their functional impact and significance as prognostic biomarkers. The nature of cytokines produced in the tumor niche and the respective tissue surroundings would determine the beneficial versus the detrimental effects of IL-17-mediated inflammation in cancer. ${ }^{11,13}$ However, much remains to be understood before we can consider Th17 a target for immune interventions in cancer therapy.

\section{Physiological roles of IL- I 7 and ThI 7 cells}

The Th17 group of cells was introduced in 2005 as a new committed lineage of CD4 cells, distinct from the
IFN- $\gamma$-producing Th1, IL-4-producing Th2, and forkhead box $\mathrm{P}^{+}{ }^{+}\left(\right.$Foxp $\left.^{+}\right)$Treg. ${ }^{14,15}$ Upon stimulation, naïve $\mathrm{T}$ cells commit to one of these Th subsets endowed with specific functions. The context in which a naïve T cell is stimulated, including the array of cytokines present and transcription factors activated, determines CD4 Th polarization. Although these different CD4 Th lineages were previously thought to be mutually exclusive, recent studies suggest Th subsets are functionally flexible. ${ }^{16}$ Th17 cells are particularly well appreciated for their plasticity. ${ }^{17}$ They can express Foxp3, produce IL-10, and become suppressive. ${ }^{18-20}$ Alternatively, Th17 cells can upregulate T-box transcription factor (TBET), produce IFN- $\gamma$, and mediate pathogenic or antitumor functions. $^{21,22}$ Nevertheless, the Th17 lineage is known for producing the iconic IL-17, as well as IL-17F, IL-22, and IL-21, which critically impact inflammation and tumor-associated immunity. ${ }^{23-25}$ The extremely dynamic nature of CD4 cell polarization is a feature of equally dynamic regulation driven by local environmental changes and epigenetics. ${ }^{17}$ Adding to Th17 instability, a variety of cell subsets have been identified as a source of IL-17 to date, highlighting the essential distinction that should be made between targeting Th17 or IL-17 as a strategy for cancer therapeutics. ${ }^{26}$

\section{Sources of IL- I7}

IL-17 is a member of the IL-17 family which also includes IL-17B, IL-17C, IL-17D, IL-17E (IL-25), and IL-17F. IL-17A and IL-17F share the most homology and are produced as homodimers $(\mathrm{A} / \mathrm{A}$ and $\mathrm{F} / \mathrm{F})$ or heterodimers $(\mathrm{A} / \mathrm{F}) .{ }^{27}$ Murine Th17 cells, which are commonly derived in vitro by activation of naïve uncommitted $\mathrm{CD}^{+} \mathrm{T}$ cells in the presence of transforming growth factor beta (TGF- $\beta$ ), IL-6, and IL-23/IL-1 $\beta$, remain rare in vivo in peripheral compartments such as blood and secondary lymphoid structures. However, they naturally concentrate in mucosal areas where they play an active role in keeping the microbial flora and pathogenic microorganisms at bay. Th17 cells are especially abundant in gut associated lymphoid tissues, where they have the crucial function, along with Treg, of allowing colonization by commensal flora without provoking tissues damage. ${ }^{28}$ Under pathologic circumstances, Th17 cells accumulate in inflamed tissues during different types of events such as infections, autoimmune diseases, or neoplasia. It is now well appreciated that IL-17 produced by Th17 cells represents only a fraction of the total IL-17. Other sources of IL-17 are innate cells, including $\gamma \delta$-T cell receptor $(\mathrm{TCR})^{+} \mathrm{T}$ cells, which are particularly potent producers of IL-17 when stimulated by IL-1 $\beta$ or IL-23, independently of TGF- $\beta$ and TCR ligation. ${ }^{29}$ To date, the other cells described as sources of IL-17 include NK cells, lymphoid tissue inducer 
cells, and innate lymphoid cells. ${ }^{26}$ Though controversial, myeloid-derived cells including polymorphonuclear cells, macrophages, and mast cells producing IL-17 have also been reported as sources. ${ }^{30-32}$ These innate immune cells could represent an early source of IL-17, intervening before the differentiation of Th17 cells and potentially influencing the ensuing Th17 response..$^{29}$ It is likely that the prognostic value of IL-17 detection in cancer differs depending on its source.

\section{ThI7 differentiation in tumor microenvironment}

\section{Plasticity of ThI7 cells}

Programming uncommitted Th cells (Th0) to become Th17 cells requires the combined action of soluble mediators (IL-6, TGF- $\beta$, and IL-23) and activation of STAT3 and retinoic acid receptor related orphan receptor gamma (ROR $\gamma \mathrm{t}$ ) transcription factors. ${ }^{33}$ Alternatively, the combination of IL-1 $\beta$, IL-6, and IL-23 has also been shown to sustain differentiation of Th17 in a TGF- $\beta$-independent manner. ${ }^{21}$ Indeed, conditional deletion of TGF- $\beta$ signaling in murine CD4 cells did not compromise Th17 differentiation in the intestinal lamina propria. ${ }^{21}$ IL-23 is involved in the maintenance of Th17 and the production of IL-17 by memory T cells, whereas TGF- $\beta$ is thought to facilitate Th17 differentiation by repressing Th1 and Th2 polarizations. ${ }^{22,34}$ TGF- $\beta$-dependent and independent Th17 cells were distinguished by distinct functions and transcription profile (Figure 1). ${ }^{21}$ IL-6 and TGF- $\beta$ induce poorly pathogenic Th17, characterized by the production of IL-10. ${ }^{20} \mathrm{IL}-23$ in vivo holds a decisive role in stabilizing the Th17 phenotype, but also in inducing pathogenic properties of Th17 cells with production of IFN- $\gamma$ and granulocyte-macrophage colonystimulating factor (GM-CSF). ${ }^{35}$ However, the dispensability of TGF- $\beta$ has faced some controversy recently, since TGF- $\beta$ is widely expressed by tissue and immune cells. Thus, it is not clear whether a TGF- $\beta$-independent Th17 commitment is physiologically relevant. ${ }^{36}$ ROR $\gamma t$ must cooperate with other transcription factors such as $\operatorname{ROR} \alpha$, STAT3, and interferon regulatory factor 4 (IRF4) to drive the differentiation of the Th17 lineage. ${ }^{37,38}$ Interestingly, other immune and metabolic conditions, including the amount of available IL-2, tryptophan metabolites (indoleamine 2,3-dioxygenase

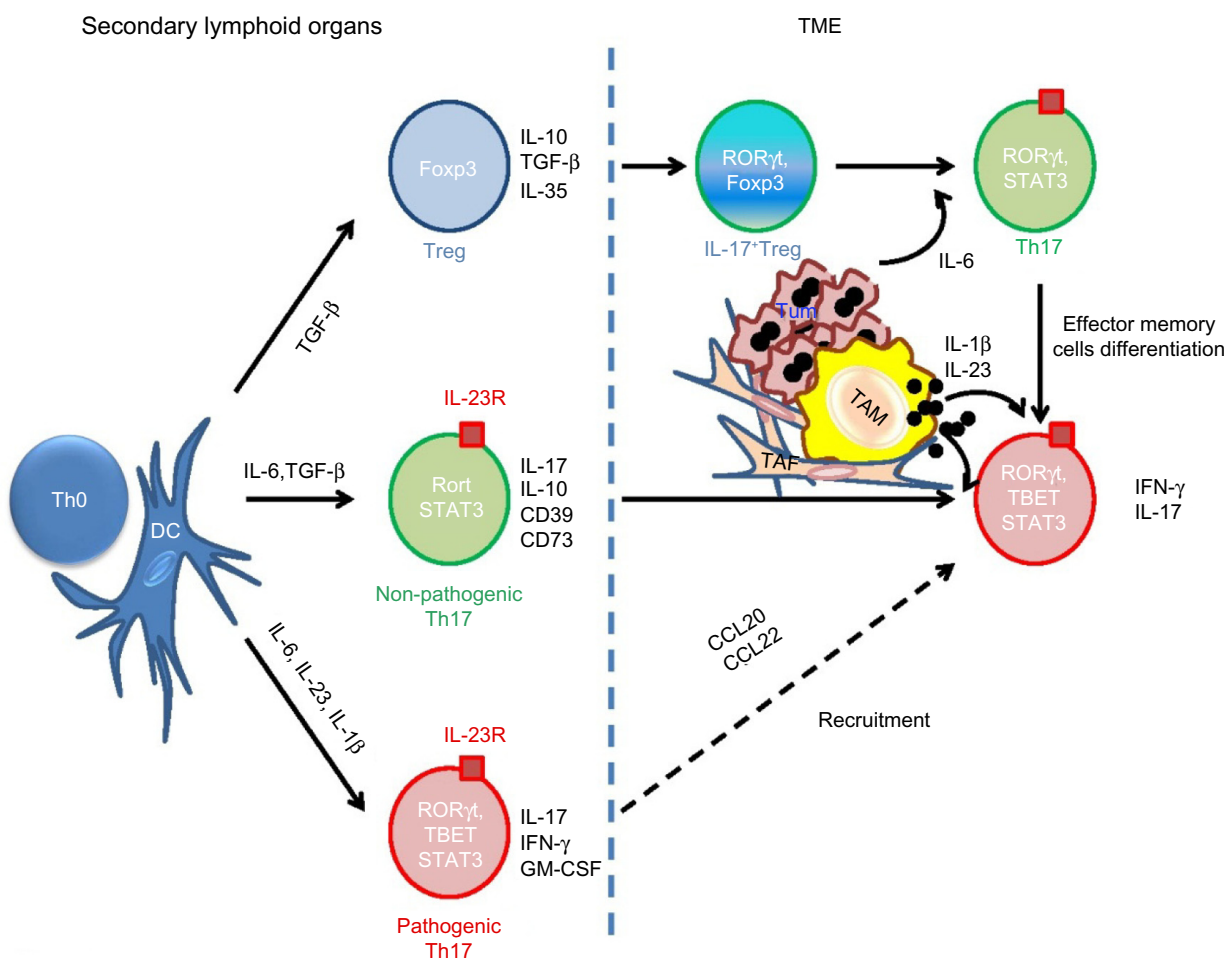

Figure I Differentiation and functional flexibility of ThI7 in TME.

Notes: DC "educate" naïv CD4+ T cells in the draining lymph nodes. DC produced TGF- $\beta$, IL-6, IL-23, and IL-I $\beta$, all necessary for ThI7 development. Th I 7 cells accumulate in the TME through the production of cytokines such as CCL20 and CCL22. In the presence of IL- 6 and low TGF- $\beta$, uncommitted Th0 cells differentiate into poorly pathogenic IL-10+ ThI7. IL-23R is therefore upregulated, allowing IL-23 to stabilize the phenotype and induce the production of IFN- $\gamma$. In tumor tissues, effector memory $\mathrm{T}$ cells can be converted into Th I7. APC such as DC and TAM are robust producers of IL-I $\beta$ and IL-23, which are involved in the polarization of Th I7 (IL- I0+ non-pathogenic/ protumoral versus IFN- $\gamma^{+}$pathogenic). Infiltrating Treg can differentiate into ThI7 in the presence of IL-6, IL-I $\beta$, and IL-23.

Abbreviations: APC, antigen-presenting cells; CCL, chemokine (C-C motif) ligand; CD, cluster of differentiation; DC, dendritic cells; Foxp3, forkhead box P3; GM-CSF, granulocyte-macrophage colony-stimulating factor; IFN- $\gamma$, interferon gamma; IL, interleukin; ROR $\gamma$ t, retinoic acid receptor related orphan receptor gamma; STAT3, signal transducer and activator of transcription 3; TAF, tumor associated fibroblast; TAM, tumor associated macrophage; TBET, T-box transcription factor; Th I7, T helper I7 cells; TGF- $\beta$, transforming growth factor beta; TME, tumor microenvironment; Treg, regulatory T cells; Tum, tumor; Th0, Th cells. 
[IDO] activity), and hypoxia present in the milieu of a neoplasm, may drive the differentiation of Th toward the Th17 lineage..$^{39-41}$ IL-2 promotes Foxp3 expression in Th17 and inhibits its differentiation via the activation of STAT5 signaling, which was shown to compete with STAT3 for binding to the promoter of $1117 a$ gene. ${ }^{39}$ Treg were demonstrated to regulate the IL-2-dependent STAT5 signaling by absorbing the IL-2 in the microenvironment, paradoxically promoting Th17 differentiation. ${ }^{42}$ Yet, Foxp $3^{+}$Treg can also regulate Th17 function through an IL-10/STAT3 pathway. ${ }^{43,44}$ Dang et al recently showed that hypoxia directs the differentiation of CD4 cells toward Th17, rather than Treg via hypoxia-inducible factor 1-alpha (HIF 1- $\alpha$ ) which activates the transcription of ROR $\gamma$ t and targets Foxp3 to proteasomal degradation. ${ }^{40}$ IDO is a tryptophan-catabolizing enzyme with potent immunosuppressive functions in the tumor microenvironment (TME), especially via its impact on Treg. ${ }^{45}$ It was recently shown that inhibition of IDO might reprogram Treg into Th17, resulting in increased $\mathrm{CD} 8^{+} \mathrm{T}$ cell infiltration and antitumor activity. ${ }^{41} \mathrm{~A}$ similar functional plasticity demonstrated by the Treg allows skewing of Foxp $3^{+}$Tregs toward Th17 in the presence of IL- $1 \beta$ or IL-23. ${ }^{46}$ Conversely, Th17 cells isolated from tumors were able to upregulate Foxp3 upon in vitro TCR-mediated stimulation and to convert to Treg with immunosuppressive functions independent of IL-10 and TGF- $\beta .{ }^{18}$ Clearly, there is a finely regulated balance between Treg and Th17 differentiation, tuned by inflammatory mediators and the metabolism of the TME. The plasticity of Th17 cells is further demonstrated by their ability to upregulate IFN- $\gamma$ and TBET, which orchestrate Th1 differentiation and mediate potent antitumor responses. Th17 or IL-17-producing $\mathrm{CD} 8^{+} \mathrm{T}$ cells ( $\mathrm{Tc} 17$ ) injected into tumorbearing mice can convert into Th1 or CTL, respectively, to promote antitumor responses. ${ }^{47,48}$ Given the aforementioned descriptions, the ontogenic and functional adaptive ability of Th17 accounts, at least in part, for the complexity of the clinical significance attributed to their detection in the TME (pro- versus anti-tumoral).

\section{The role of antigen-presenting cells in ThI 7 polarization} It is not yet fully understood what factors in the TME turn $\mathrm{CD} 4+$ Th into "bad" or "good" Th17 cells. The nature of antigen-presenting cells (APC) and their cytokine profiles (IL-1 $\beta$, IL-23, or TGF- $\beta$ ), which induce Th17 in regional lymph nodes or in tumor tissues, is thought to dictate the functional properties of Th17 in these tissues. APC and especially dendritic cells (DC), which are mainly involved in the education of naïve $\mathrm{T}$ cells in the lymph nodes, are also important sources of TGF- $\beta$ in the TME. Integrin $\alpha v \beta 8$ on DC was shown to play an important role in TGF- $\beta$ activation and Th17 differentiation since mice lacking $\alpha v \beta 8$ were fully protected from Th17-dependent experimental autoimmune encephalomyelitis. ${ }^{49}$ Th17 can also be generated in the TME from effector memory cells. Studies have shown that tumor-associated macrophages (TAM) and resident DC are efficient in inducing antitumor Th17 response in ovarian cancer. ${ }^{50,51}$ Tumor-associated macrophages were especially potent inducers of Th17 polarization through the production of IL- $1 \beta$, in the TME, whereas blocking IL- 6 or TGF- $\beta$ did not affect Th17 polarization and IL-23 was barely detectable in ascites produced by ovarian carcinomas. ${ }^{50} \mathrm{IL}-1 \beta$ produced by APC in tumor lesions can contribute to the differentiation of antitumor skewed Th17 cells, which produce IFN- $\gamma$ and induce the recruitment of effector cells. ${ }^{51}$ Divergently, blocking IL-23 was shown to dramatically mitigate IL-17 production, impeding carcinogenesis in a murine model of colitis-associated cancer. ${ }^{52}$ It is possible that the differential amount of TGF- $\beta$, IL-23, and/or IL-1 $\beta$ in the TME of these types of cancers may lead to functionally distinct Th17 subsets. Taken together, these studies suggest that influencing the recruitment and nature of APC (eg, producers of TGF- $\beta$, IL-23, and IL-1 $\beta$ ) in the TME may become an effective strategy to improve antitumoral immunity. ${ }^{53}$

\section{ThI 7 and IL-I 7 functions in cancer}

IL-17 is a pleiotropic proinflammatory cytokine whose impact in tumor progression is highly context-dependent. However, discrepancies observed regarding its role in the TME seem to be largely dependent on the experimental model utilized: transplantable tumors versus de novo carcinogenesis; ${ }^{54,55}$ lymphopenic versus immunocompetent systems; ${ }^{47,56-58}$ overexpressed IL-17 versus endogenous IL-17 (Table 1)..$^{55,57}$

\section{IL-I 7 receptor signaling}

Th17 are largely devoid of the effector molecules granzyme and perforin, suggesting that they do not exert effector functions by themselves. Instead, Th17 cells are proinflammatory as a result of their signature cytokines IL-17 and IL-17F, which mediate the recruitment of effector lymphocytes and phagocytes that dispose compromised cells and pathogens. They also play an active role in tissue repair. Although more work needs to be done to delineate the differential inflammatory properties of IL-17 and IL-17F, recent experimental models of inflammation using selective genetic ablation of either $I l 17 a$ or $I l 17 f$ genes showed that both cytokines mediate distinct proinflammatory functions. 
Table I List of experimental murine models analyzing the roles of IL-I7/IL-23 in tumor immunity

\begin{tabular}{|c|c|c|c|c|c|c|}
\hline Cancer type & $\begin{array}{l}\text { Tumor } \\
\text { tissue }\end{array}$ & $\begin{array}{l}\text { Immune } \\
\text { mediator }\end{array}$ & Functional analysis & Outcome & Statistics & Ref \\
\hline Melanoma & $\mathrm{B} 16$ & ThI7 & $\begin{array}{l}\text { ThI7 }>\text { ThI for tumor eradication; } \\
\text { IFN- } \gamma \text {-dependent }\end{array}$ & Positive & $\begin{array}{l}\text { One-way ANOVA with Bonferroni } \\
\text { correction (vitiligo) }\end{array}$ & 47 \\
\hline Melanoma & $\mathrm{B} 16$ & ThI7 & $\begin{array}{l}\text { Treg converted to Th } 17 \text { by IL- } 6 \\
\text { from pDC } \\
\text { Increased CD8+ T cells and } \\
\text { antitumor effect }\end{array}$ & Positive & $\begin{array}{l}\text { Tukey honestly significant difference } \\
\text { test }\end{array}$ & 41 \\
\hline Melanoma & $\mathrm{B} 16$ & Tcl7 & $\begin{array}{l}\text { Adoptive transfer of Tcl7; enhanced } \\
\text { antitumor immunity }\end{array}$ & Positive & None & 93 \\
\hline Melanoma & $\mathrm{BI} 6-\mathrm{FIO}$ & ThI7 & $\begin{array}{l}\text { Adoptive transfer ThI7 cells; } \\
\text { CCL20-dependent DC and CTL } \\
\text { recruitment; decreased tumor growth }\end{array}$ & Positive & Student's $t$-test, $n=4-5$ mice & 53 \\
\hline Melanoma & $\mathrm{B} 16$ & IL-23 & $\begin{array}{l}\text { IL-23 as vaccine adjuvant; tumor- } \\
\text { specific CD8+ T cell responses }\end{array}$ & Positive & $\begin{array}{l}\text { ANOVA-repeated measures test } \\
\text { and Wilcoxon's rank-sum test; } \\
\text { Nonparametric Kruskal-Wallis } \\
\text { test; } n=5\end{array}$ & 88 \\
\hline Colon & MC38 & ThI $7 / I L-17$ & $\begin{array}{l}\text { Increased tumor growth in IL-I7- } \\
\text { deficient mice }\end{array}$ & Positive & Mann-Whitney $U$ and $\chi^{2}$ tests; $n=5$ & 55 \\
\hline Ovarian & ID8 & ThI7 & $\begin{array}{l}\text { Increased tumor growth; myeloid cell } \\
\text { recruitment }\end{array}$ & Negative & $\begin{array}{l}\text { Two-tailed Student's } t \text {-test with } \\
\text { Welch's correction or } \\
\text { Mann-Whitney test; } n=60\end{array}$ & 64 \\
\hline Fibrosarcoma & CMS-G4 & $\mathrm{IL}-17 / \gamma \delta-\mathrm{T}$ & $\begin{array}{l}\text { IL- I7-producing } \gamma \delta+T \text { cells } \\
\text { promoted angiogenesis }\end{array}$ & Negative & $\begin{array}{l}\text { Two-tailed Student's } t \text {-test (tumor } \\
\text { volume); } \mathrm{n}=5\end{array}$ & 66 \\
\hline Skin & DMBA/TPA & IL-I7 & $\begin{array}{l}\text { Decreased tumor in IL-I } 7 \text { KO mice; } \\
\text { STAT3-dependent }\end{array}$ & Negative & $\begin{array}{l}\text { Unpaired } t \text {-test (WT, } \mathrm{n}=19 \text {; } \\
\mathrm{IL}-17-/-, \mathrm{n}=\mathrm{II})\end{array}$ & 54 \\
\hline Melanoma & $\begin{array}{l}\text { BI6 and } \\
\text { MB49 }\end{array}$ & ThI7 & $\begin{array}{l}\text { Th I7 promotes tumor growth; } \\
\text { IL-6/STAT3-dependent }\end{array}$ & Negative & $\begin{array}{l}\text { Unpaired } t \text {-test. Two-way ANOVA } \\
\text { test (tumor growth) }\end{array}$ & 60 \\
\hline $\begin{array}{l}\text { Cervical } \\
\text { cancer }\end{array}$ & $\mathrm{HeLa}, \mathrm{ICI}$ & IL-I7 & $\begin{array}{l}\text { IL-I } 7 \text { increases tumor cell growth in } \\
\text { nude mice }\end{array}$ & Negative & $\begin{array}{l}\text { Mann-Whitney test (tumor size); } \\
n=8-10\end{array}$ & 58 \\
\hline NSCLC & $\begin{array}{l}\text { Variety cell } \\
\text { lines }\end{array}$ & IL-I7 & $\begin{array}{l}\text { CXCR2-dependent angiogenesis in } \\
\text { SCID mice }\end{array}$ & Negative & $\begin{array}{l}\text { Unpaired two-tailed Student's } t \text {-test } \\
\text { (tumor volume) } n=7\end{array}$ & 61 \\
\hline Multiple & $\begin{array}{l}\text { Variety cell } \\
\text { lines }\end{array}$ & IL-I7 & $\begin{array}{l}\text { IL-I } 7 \text { promotes tumor growth; } \\
\text { MDSC recruitment }\end{array}$ & Negative & Two-tailed Student $t$-test; $\mathrm{n}=5$ & 62 \\
\hline Multiple & $\begin{array}{l}\text { Variety of cell } \\
\text { lines }\end{array}$ & IL-I7 & $\begin{array}{l}\text { Resistance to anti-VEGF therapy via } \\
\text { G-CSF-mediated MDSC recruitment }\end{array}$ & Negative & Two-tailed Student's $t$-test; $n=5-8$ & 63 \\
\hline $\begin{array}{l}\text { Fibrosarcoma, } \\
\text { colon }\end{array}$ & $\begin{array}{l}\text { MCA205, } \\
\text { MC38 }\end{array}$ & IL-I7 & $\begin{array}{l}\text { IL- I } 7 \text { promotes angiogenesis via } \\
\text { stimulation of vascular endothelial } \\
\text { cell migration and induction of pro- } \\
\text { angiogenic factors }\end{array}$ & Negative & $\begin{array}{l}\text { Unpaired two-tailed Student's } t \text {-test; } \\
n=6-7\end{array}$ & 57 \\
\hline Melanoma & $\mathrm{BI} 6-\mathrm{FIO}$ & IL-I7 & PPAR $\gamma$-induced SOCS3 prevents & Negative & Mann-Whitney $U$ test and comparison & 67 \\
\hline Breast cancer & $4 \mathrm{TI}$ & & IL-I7-mediated cancer growth & & $\begin{array}{l}\text { of categorical data by Fisher's exact } \\
\text { test }\end{array}$ & \\
\hline Multiple & $\begin{array}{l}\text { Variety of cell } \\
\text { lines }\end{array}$ & IL-23 & $\begin{array}{l}\text { IL-23 promotes tumor incidence } \\
\text { and growth }\end{array}$ & Negative & $\begin{array}{l}\text { Student's } t \text {-test; Kruskal-Wallis test/ } \\
\text { Dunn's multiple comparison test/ } \\
\text { Tukey's multiple comparison test/ } \\
\text { Wilcoxon matched pairs test; } n=3-7\end{array}$ & 87 \\
\hline
\end{tabular}

Abbreviations: ANOVA, analysis of variance; CCL, chemokine (C-C motif) ligand; CTL, cytotoxic T lymphocytes; CXCR, chemokine (C-X-C motif) receptor; CD8, cluster of differentiation 8; DC, dendritic cells; DMBA, 7,I2-dimethylbenz-alpha-anthracene; G-CSF, granulocyte colony-stimulating factor; IFN- $\gamma$, interferon gamma; IL, interleukin; KO, knockout; MDSC, myeloid-derived suppressor cells; NSCLC, non-small-cell lung carcinoma; pDC, plasmacytoid dendritic cells; PPAR $\gamma$, peroxisome proliferator-activated receptor gamma; SCID, severe combined immunodeficiency; SOCS3, suppressor of cytokine signaling 3; STAT3, signal transducer and activator of transcription 3; TcI7, Th I7 or IL-I7-producing CD8 ${ }^{+}$T cells; Th, T helper; TPA, I2-O-tetradecanoyl-phorbol-I3-acetate; Treg, regulatory T cells; VEGF, vascular endothelial growth factor.

IL-17F, but not IL-17, knockout (KO) mice exhibit defective airway neutrophilia in response to allergen. ${ }^{59}$ The molecular mechanisms of their functional specificity are not yet understood since they signal through the same heterodimeric IL-17R subunit A/subunit C (IL-17RA/C) receptor and are biologically active as homodimers as well as heterodimers. IL-17R signaling leads to the activation of the nuclear factor-kappa $\beta(\mathrm{NF}-\kappa \mathrm{B})$ pathway via the interaction of IL-17RA with the adaptor molecule tumor necrosis factor (TNF) receptor associated 
factor 3 (TRAF3) interacting protein 2 (TRAF3P2 or ACT1) and the TRAF6. ${ }^{27}$ In contrast to other cytokines, IL-17/ IL-17R signaling does not directly use the Janus kinase (JAK) and STAT transduction routes, but rather induces an indirect activation of the protumoral STAT3 pathway through an IL-6/STAT3 feedforward loop. ${ }^{54,60}$ IL-17R is widely expressed in epithelial cells, fibroblasts, endothelial cells, and hematopoietic cells, mediating IL-17 pleiotropic properties widely in the TME. ${ }^{27}$

\section{Recruitment of immune effector cells}

IL-17 signals epithelial cells and fibroblasts to produce growth factors and a large array of chemokines, which are critical for the immune polarization mediating protumoral versus antitumoral effects. Indeed, in some cancers, such as in the case of non-small-cell lung carcinomas (NSCLC), cervical cancers, or colorectal cancers (CRC), IL-17 induces the secretion of chemokine (C-X-C motif) ligand 1 (CXCL1), CXCL2, CXCL5, and CXCL8, mediating the recruitment of neutrophils, macrophages, and immature myeloid cells, well known for their protumoral function. ${ }^{58,61}$ Conversely, other groups have shown that genetic ablation of IL-17 signaling impairs tumor growth through decreased myeloid-derived suppressor cells (MDSC) accumulation and increased cytotoxic $\mathrm{CD} 8^{+}$ $\mathrm{T}$ cell infiltration. ${ }^{54,62-64}$ Also, other tumors such as ovarian carcinomas produce CXCL9 and CXCL10 in the presence of IL-17, which attract effector cells like $\mathrm{CD} 8^{+} \mathrm{CTL}$ and NK cells to mediate antitumor immune response. ${ }^{50} \mathrm{IL}-17$ contributes also to the recruitment of APC such as DC via the induction of chemokine (C-C motif) ligand 20 (CCL20) production in the tumor bed. ${ }^{53,65}$ Adoptive transfer of tumor-specific Th17 in a model of pulmonary melanoma showed a dramatic reduction of lung metastasis associated with a CCL20-dependent recruitment of DC and activation of CD8 ${ }^{+} \mathrm{CTL} .{ }^{53}$ These observations unravel that according to the type of cancer cells, activation by IL-17 can lead to opposite effects via the induction of a distinct array of chemokines by target cells.

\section{Angiogenesis}

In a lymphopenic system missing adaptive immunity, IL-17 demonstrated protumoral properties by sustaining angiogenesis and tumor growth. ${ }^{58}$ Indeed, IL-17 is a pro-angiogenic factor that induces neovascularization and tumor growth via the direct induction of VEGF and angiogenin-2 production by stromal (myeloid cells and fibroblasts) and epithelial cells. ${ }^{57,60,63,66,67}$ IL-17 can similarly facilitate tumor angiogenesis independently of VEGF via its action on the tumorassociated stromal cells. ${ }^{63,67}$ Chung et al's group showed that IL-17 can activate tumor-associated fibroblasts (TAF) to secrete granulocyte colony-stimulating factor (G-CSF), which in turn attract myeloid cells that produce angiogenic mediators such as prokineticin 2/Bv8, matrix metalloproteinase 9 (MMP9), as well as the proinflammatory S100A8/9 molecules. ${ }^{63}$ Importantly, IL-17 also mediates protumoral effects indirectly through the IL-6/STAT3 signaling, promoting the expression of genes involved in cell proliferation and survival (eg, Cyclin D1, Bcl-xl, or survivin). ${ }^{60}$

\section{ThI7-induced tumorigenesis}

Two recent experimental models of colitis demonstrated the contribution of the IL-23/Th17 axis in colon tumorigenesis. ${ }^{52,68} \mathrm{Wu}$ et al were able to reduce enterotoxigenic Bacteroides-fragilisdriven colon tumorigenesis in mice with heterozygous null mutation of adenomatous polyposis coli (Apc) gene ( $\mathrm{Min}^{A p c-/+}$ mice) via neutralization of IL-23R and IL-17. ${ }^{68}$ Grivennikov et al showed that genetic deletion of IL-17R or IL-23 deficiency in myeloid cells reduced the tumor burden in $\mathrm{Min}^{A p c-/+}$ mice. ${ }^{52}$ The authors proposed that barrier breach provoked by colonic tumors triggered IL-23 production by myeloid cells and Th17 polarization, although the molecular mechanisms sustaining the tumorigenic activities of IL-17 remain largely unknown. Nevertheless, these experimental data concur with the observations made in human CRC, where the IL-17/Th17 signature is associated with diminished survival of patients. ${ }^{13}$

In summary, despite the fact that Th17 cells make up a small part of circulating $\mathrm{CD}^{+} \mathrm{T}$ cells (in mice and humans), they accumulate in the TME of most solid tumors when compared to normal counterpart tissues. Different subsets of Th17 (IFN- $\gamma^{+}$versus IL-10 ${ }^{+}$) are endowed with distinct functions in regards to their ability to promote tumors or, conversely, eliminate tumors. Th17 exercise their opposing functions depending on the features of the TME (nature of the APC, presence of TGF- $\beta$, IL- $1 \beta$ or IL-23). These cells can mediate antitumoral effects by their ability to recruit immune effector cells (CTL, NK, DC) into the tumor bed and they can promote tumor growth by means of angiogenesis (production of VEGF, angiogenic chemokines) and/or through immunosuppression (Treg conversion, MDSC recruitment) (Figure 2). Th17 cells are functionally unstable and capable of converting into Treg or Th1-type cells causing antagonistic consequences in tumor immunity. Moreover, discrepancies have been found when comparing the development of Th17 in humans as opposed to murine models, emphasizing the need to exercise caution when extrapolating between species. ${ }^{69}$ The preceding described aspects of the Th17 biology account for the complexity of IL-17/Th17 significance in human cancer 


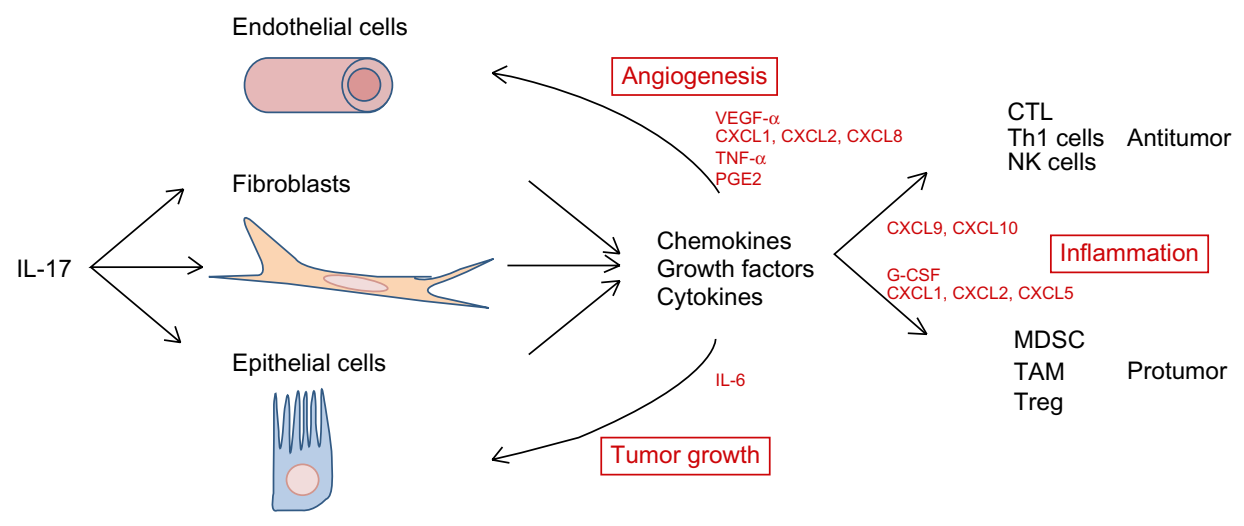

Figure 2 Role of IL-I7 in tumor progression.

Notes: IL-I7 in the TME initiates the recruitment of immune effectors through the induction of chemokines, cytokines, and growth factors secretion by tumor cells, tumorinfiltrating fibroblasts (TAF), and endothelial cells. IL-I7 induces the production by tumor cells of CXCL9 and CXCLI0, which recruit NK cells and CTL or CCL20, which recruits DC, to mediate antitumor immune response. IL-I7 also triggers the production of CXCLI, CXCL5, and CXCL8 by other types of tumors and TAF to mediate pro-angiogenic activities. VEGF and PGE2, produced by tumor cells and TAF, also contribute to angiogenesis and tumor growth. G-CSF produced by tumor cells and TAF will impact the recruitment of myeloid progenitors and disturb local granulopoiesis, resulting in the accumulation of MDSC. Finally, IL-I7/IL-I7R interactions lead to the production of IL-6, an important tumor growth and survival factor, via the activation of the oncogenic STAT3.

Abbreviations: $\mathrm{CCL}$, chemokine (C-C motif) ligand; CTL, cytotoxic T lymphocytes; CXCL, chemokine (C-X-C motif) ligand; DC, dendritic cells; G-CSF, granulocyte colony-stimulating factor; IL, interleukin; MDSC, myeloid-derived suppressor cells; NK, natural killer; PGE2, prostaglandin E2; STAT3, signal transducer and activator of transcription 3; TAF, tumor associated fibroblasts; TAM, tumor associated macrophages; ThI, T helper I; TME, tumor microenvironment; TNF, tumor necrosis factor; Treg, regulatory $T$ cells; VEGF, vascular endothelial growth factor.

and the uncertainty of using this biomarker for therapeutic purposes.

\section{Clinical implications}

Th17 cells are key players in inflammation and autoimmune disorders; however, the clinical significance of their detection in the TME remains unclear. The phenotypic and functional heterogeneity of the Th17 lineage along with its functional plasticity underscore the context-dependency of their prognostic and therapeutic implications as a cancer-associated biomarker (cancer type and stage, infiltration density, nature, and location). Importantly, in light of recent studies seeking to demonstrate a link between IL-17 detection and cancer promotion (Table 2), a distinction should be made between IL-17 and Th17. A variety of cell types characterized by distinct cytokine profiles and effector functions are able to produce IL-17. Many reports state that IL-17 protein and/or messenger RNA (mRNA) are detected in tumor beds, but the cellular sources of production were often not characterized. ${ }^{70}$

\section{The prognostic value of IL-I 7 and/or ThI7 in cancer}

\section{Blood versus tumor tissues}

A growing list of cancers has recently been investigated for the presence of Th17 cells in order to gain insight about the clinical significance of their existence in tumor lesions. However, while most of the studies have been performed with peripheral blood from patients, Th17 cells accumulate predominantly in the neoplastic sites. Yamada et al recently showed the preferential accumulation of Th17 cells in gastric cancer lesions compared to peripheral blood and normal gastric tissue specimens. ${ }^{71}$ They also found a strong negative correlation between high level of IL-17 in the sera of gastric cancer patients and their 5-year survival. ${ }^{71}$ Unfortunately, they did not address the prognostic value of having IL-17 and/or Th17 detected in stomach samples. Meanwhile, an earlier study performed by Chen et al found that gastric cancer patients expressing higher levels of intratumoral IL-17 had a better survival. ${ }^{72}$ Despite relative ease of accessibility, the blood compartment is probably not representative of the intratumoral Th17 response, and investigations should concentrate on determining the clinical impact of tumor infiltrating IL-17-producing cells. Kryczek et al published one of the first comprehensive analyses characterizing tumor infiltrating Th17 cells and demonstrated that IL-17 is a positive prognostic marker of antitumor immune response in ovarian carcinomas. ${ }^{50}$ They showed that although no significant difference could be found between normal and cancer patient blood samples, the prevalence of Th17 among $\mathrm{CD}^{+} \mathrm{T}$ cells was much higher in tumor tissues. Th17 are recruited, induced, or expanded in the TME via the production of mediators by tumor and/or stromal cells. Interestingly, the detection of IL-17 (and not Th17 per se) in ovarian cancer ascites has been correlated with an increased survival of patients. The authors of this study made an elegant charinacterization of the infiltrating Th17 showing a lack of CD25, human leukocyte antigen (HLA)-DR, and granzyme, therefore distinguishing them from 


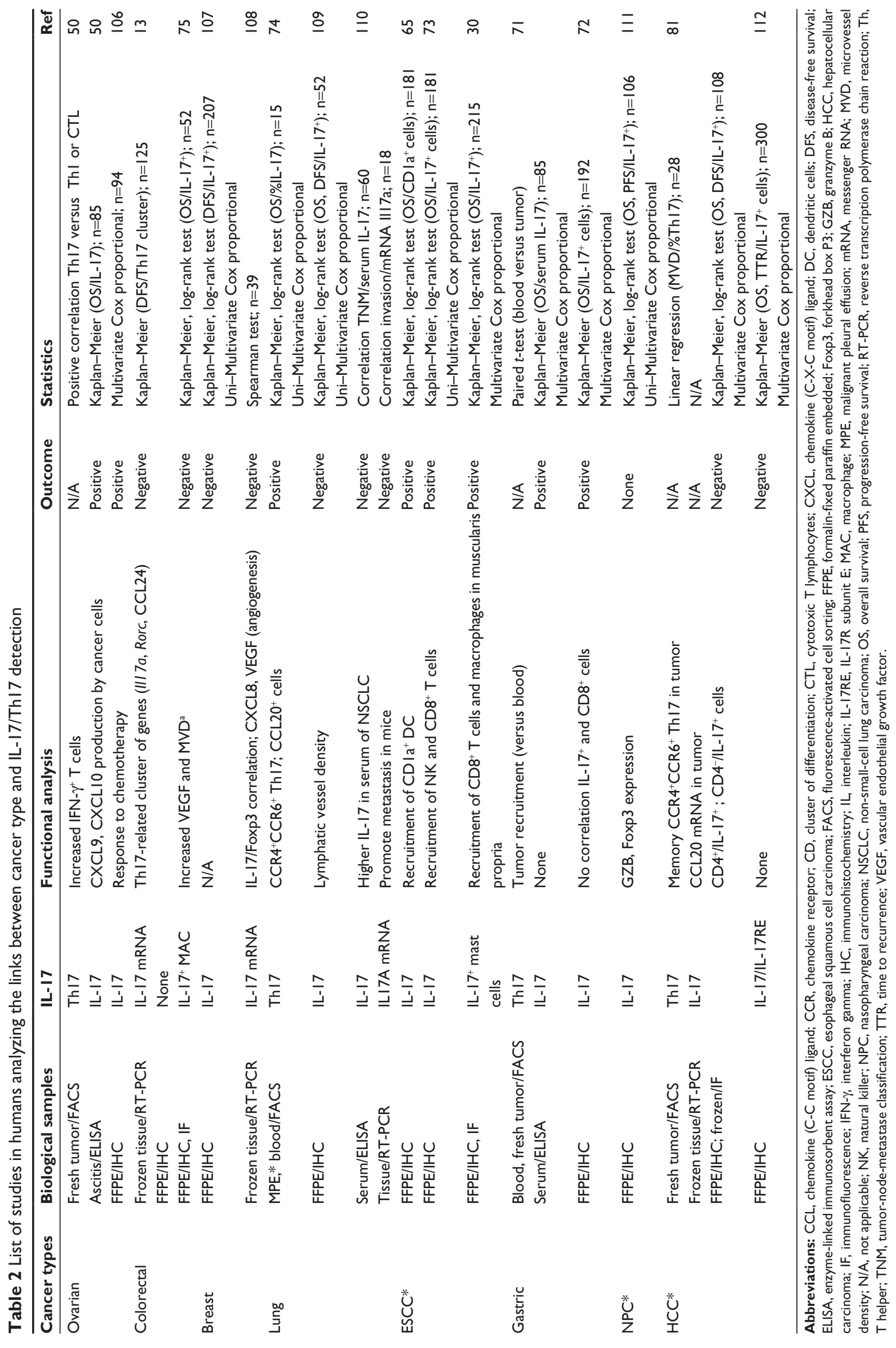


conventional effector cells. Of note, these Th17 cells produced IFN- $\gamma$, IL-2, and TNF- $\alpha$, but no IL-10. ${ }^{50}$

\section{Intratumoral IL-I 7 and chemokines}

Kryczek et al found in their study that ovarian tumor cells produced CXCL9 and CXCL10, which recruited immune effectors into the tumor bed. ${ }^{50}$ No correlation was observed between Th17 and neutrophils, eosinophils, macrophages, or DC. They instead established a correlation with $\mathrm{CD} 8^{+} \mathrm{T}$ cells and NK infiltration, well known for their active participation in antitumor immune responses..$^{50}$ Similar results have been described in esophageal squamous cell carcinoma (ESCC) and lung cancer. ${ }^{65,73,74}$ Though Lu et al did not characterize Th17 per se, they reported that the number of IL-17producing cells correlated with a higher number of $\mathrm{CD} 8^{+} \mathrm{T}$ and NK cells invading the tumor area. ${ }^{65}$ Interestingly, they were able to positively link the number of IL-17-producing cells with the recruitment of $\mathrm{CD} 1 \mathrm{a}^{+} \mathrm{DC}$, a mechanism that seems to be associated with the capacity of ESCC cells to produce CCL20 upon IL-17 stimulation. ${ }^{65}$ Patients showing a high density of $\mathrm{CD} 1 \mathrm{a}^{+} \mathrm{DC}$ were found to have a better survival. These results were in line with those obtained by Martin-Orozco et al, who discovered that the adoptive transfer of Th17 cells in a murine model of melanoma lung metastasis was related to the recruitment of DC in a CCL20/ chemokine receptor 6 (CCR6)-dependent manner. ${ }^{53}$ In lung cancer, a high Th17 frequency detected in malignant pleural effusions was positively correlated with patients' survival, ${ }^{74}$ and CCL20 was shown to be a key chemotactic mediator produced by tumor cells in the recruitment of CCR6 $6^{+}$ Th17. ${ }^{74}$ The positive association between IL-17 or Th17 and cancer patient survival demonstrated in these different types of cancers (ovarian, lung, and esophageal) is due to the role of IL-17 in shaping the chemokine milieu via its interaction with tumor cells or tumor-associated stromal cells (fibroblast or myeloid cells). On the one hand, IL-17 can promote the production of angiostatic CXCL9 and CXCL10 (and not VEGF) by ovarian cancer cells, but, on the other hand, IL-17 can induce the production of angiogenic VEGF, CXCL1, or CXCL8 (and repressed CXCL9 or CXCL10) in CRC cells. ${ }^{75,76}$ IL-17 in NSCLC patients was associated with detection of CXCL1, CXCL5, or CXCL8. ${ }^{61}$ Furthermore, the

Table 3 Drugs affecting IL-I7 and ThI7 functions in preclinal and clinical development

\begin{tabular}{|c|c|c|c|}
\hline Drugs & Properties & Company & Applications \\
\hline \multirow[t]{2}{*}{ Secukinumab } & Anti-IL-I7A & AIN457 (Novartis) & Psoriasis, RA, MS, ankylosing spondylitis \\
\hline & Humanized mAb & & (Phase III) \\
\hline \multirow[t]{2}{*}{ Ixekizumab } & Anti-IL-I7A & Ly243982I (Eli Lilly) & Psoriasis, RA, ankylosing spondylitis \\
\hline & Humanized mAb & & (Phase II) \\
\hline \multirow[t]{2}{*}{ Brodalumab } & Anti-IL-I7R & AMG-827 (Amgen) & Psoriasis, RA, asthma (Phase II) \\
\hline & Human mAb & & \\
\hline \multirow[t]{2}{*}{ Briakinumab } & Anti-IL-12/p40 & ABT-874 (Abbott) & Withdrawn \\
\hline & Human mAb & & \\
\hline \multirow[t]{2}{*}{ Ustekinumab } & Anti-IL-I2/p40 & Stelara ${ }^{\circledR}$ (Janssen Biotech Inc) & Psoriasis, psoriasis arthritis \\
\hline & Human mAb & & \\
\hline MP-I96 & IL-23/pI9 & Effimune & N/A \\
\hline \multirow[t]{2}{*}{ Tocilizumab } & Anti-IL-6R & Actemra ${ }^{\circledR}$ (Genentech) & RA \\
\hline & Humanized mAb & & \\
\hline Anakinra & IL-IR antagonist & Kineret $^{\circledR}$ (Amgen) & RA, NOMID \\
\hline OPB-3II2I & STAT3 inhibitor & OPB-3II2I (Otsuka Pharmaceutical) & Advanced cancer (Phase I) \\
\hline OPB-5I602 & STAT3 inhibitor & OPB-5I 602 (Otsuka Pharmaceutical) & Advanced cancer (Phase I) \\
\hline AZD9I50 & STAT3 inhibitor & AZD9I50 (ISIS Pharmaceutical) & $\begin{array}{l}\text { Advanced cancer, lymphoma, HCC } \\
\text { (Phase I/II) }\end{array}$ \\
\hline SRIO0I & ROR inhibitor & Preclinical development & N/A \\
\hline Vidofludimus & DHODH inhibitor & 4SC-IOI (4SCAG) & Crohn's disease, UC (Phase II) \\
\hline Tofacitinib & JAK inhibitor & Xeljanz $^{\circledR}$ (Pfizer) & RA \\
\hline Vorinostat & HDAC inhibitor & Zolinza $^{\circledR}$ (Merck) & CTCL \\
\hline Romidepsin & HDAC inhibitor & Istodax ${ }^{\circledR}$ (Celgene) & CTCL \\
\hline
\end{tabular}

Notes: Secukinumab: Novartis International AG, Switzerland; Ixekizumab: Eli Lilly and Company, Indianapolis, IN, USA; Brodalumab: Amgen, Thousand Oaks, CA, USA; Briakinumab: Abbott Park, North Chicago, IL, USA; Ustekinumab: Janssen Biotech, Inc., CA, USA; MP-196: Effimune, Nantes, France; Tocilizumab: Actemra ${ }^{\circledR}$ (Genentech), CA, USA; Anakinra: Amgen; OPB-3II2I: Otsuka Pharmaceutical, Tokyo, Japan; OPB-5I602: Otsuka Pharmaceutical; AZD9I50: Isis Pharmaceuticals Inc., San Diego, CA, USA; Vidofludimus: 4SC, Munich, Germany; Tofacitinib: Xelianz ${ }^{\circledR}$ (Pfizer), New York, NY, USA; Vorinostat: Zolinza ${ }^{\circledR}$ (Merck), Rahway, NJ, USA; Romidepsin: Istodax ${ }^{\circledR}$ (Celgene), Summit, NJ, USA.

Abbreviations: CTCL, cutaneous T cell lymphoma; DHODH, dihydroorotate dehydrogenase; HCC, hepatocellular carcinoma; HDAC, histone deacetylase; IL, interleukin; JAK, Janus kinase; mAb, monoclonal antibody; MS, multiple sclerosis; N/A, not applicable; NOMID, neonatal onset multisystem inflammatory disease; RA, rheumatoid arthritis; ROR, retinoic acid receptor related orphan receptor; STAT3, signal transducer and activator of transcription 3; UC, ulcerative colitis. 
administration of recombinant CXCL10 improved the survival of NSCLC-bearing severe combined immunodeficiency (SCID) mice and injection of anti-CXCR2 (CXCL1, CXCL5, and CXCL8 receptor) $\mathrm{mAb}$ blocked the protumoral effect of IL-17. ${ }^{61,77}$ In concordance with these results, the density of pro-angiogenesis IL- $17^{+}$cells in CRC and NSCLC correlated with poor prognosis for these patients. ${ }^{13}$ Recently, a large intergene correlation study performed in CRC patients looking for genes highly associated with tumor-infiltrating memory $\mathrm{T}$ cells and effector $\mathrm{T}$ cells (antitumor immune signature) identified CXCL9 and CXCL10 genes at the top of the list. ${ }^{78}$ This finding concurred with the observation that IL-17, which does not induce the production of these angiostatic chemokines by CRC cells, is associated with poor prognosis in this type of malignancy. ${ }^{13}$ It is therefore tempting to postulate that knowing the sensitivity of the different tumor types to IL-17 may allow clinicians to predict whether infiltrating Th17 would be beneficial or deleterious for patient survival. Unfortunately, the pleiotropic IL-17 targets not only epithelial/tumoral cells but also stromal cells, including fibroblast (TAF), endothelial cells, and myeloid-derived cells, which can also polarize tumor immune responses toward tumor promotion or tumor eradication (Figure 2). TAF have been shown to promote tumor-associated angiogenesis when stimulated by IL-17 through the G-CSF-dependent recruitment of MDSC. ${ }^{63}$ IL-17 has also been found to be capable of directly activating the immunosuppressive function of MDSC and monocytes. ${ }^{62,79}$

\section{Heterogeneity of intratumoral ThI7}

Th17 cells are functionally heterogeneous and different Th17 subsets may have a distinct impact on tumor progression. Zhao et al recently demonstrated that $\mathrm{CCR} 4^{+} \mathrm{CCR} 6^{+} \mathrm{Th} 17$, but not CCR4-CCR6 ${ }^{+}$Th17, were able to inhibit the proliferation and IFN- $\gamma$ production by $\mathrm{CD} 8^{+} \mathrm{T}$ cells in hepatocellular carcinoma (HCC) patients. ${ }^{80}$ This study was performed in the peripheral blood compartment and it would be informative to characterize these Th17 subsets in the tumor tissue and link their detection with antitumor immune responses. On this note, Zhang et al previously showed that, despite CCR6 expression by virtually all Th17 in blood and tumors of HCC patients, a higher proportion of them expressed CCR4 in the tumor tissue. ${ }^{81}$ Though the cohort included a relatively limited number of patients, they showed that CCR4 expression was significantly increased according to the stage of the disease. Here again, the expression of CCR 4 and CCR6 on Th17 was associated with higher levels of CCL20 and CCL22 in tumor tissue compared to normal counterparts. This suggests that the density of Th17 cells and the differential representation of each Th17 subset in tumor tissue may be driven by a CCL20/ CCL22-dependent recruitment mechanism. Therefore, additional functional markers (eg, CCR4 and CCR6) could be used to characterize intratumoral Th17 and further stratify the clinical value of their detection in tumors. ${ }^{12,78}$

\section{ILI7 and immune contexture}

The nature and anatomic localization of IL- $17^{+}$cells in the tissue have also been recently appreciated as an important factor in determining clinical prognosis. ${ }^{12,30}$ There are numerous prospective clinical studies looking at the penetration of this subset of $\mathrm{T}$ helper cells in cancer tissues raising the concern of utilizing IL-17 detection versus Th17 cells as prognostic markers. Since IL-17 is produced by a variety of adaptive and innate immune cells, it seems that the characterization of $\mathrm{IL}-17^{+}$cells, and not only Th17, should be performed (Table 1). IL-17 mediates different types of effects depending on whether it is being produced by Th17, $\gamma \delta$-T cells, macrophages, or mast cells dictated by the nature of the cytokines and growth factors co-produced by these cells. Th17 cells are capable of producing other proinflammatory cytokines such as IL-21 or IFN- $\gamma$, which can attract immune effector cells (CTL and NK) to promote an antitumor immune response. In turn, macrophages can provide the TME with a variety of angiogenic (VEGF, TNF- $\alpha$ ) and protumoral mediators (IL-6). ${ }^{30,31,82}$ Wang et al described that IL-17-producing mast cells in ESCC were mainly concentrated in the muscularis propria and their density predicted a better outcome of the disease by means of recruiting more effector $\mathrm{CTL}$ and macrophages to the area. ${ }^{30}$ This distribution of immune effector cells is different in CRC, where the IL- $17^{+}$cells accumulate in the lamina propria and indicate a poor prognosis. ${ }^{13}$ These reports show that not only the functional properties of IL-17 are important, but also that the context in which this proinflammatory cytokine is being produced is critical. Galon et al recently introduced the concept of immune contexture in cancer, which defines the density, functional polarization, localization (core versus invasive margin) of the immune infiltration. ${ }^{83}$ They demonstrated the profound impact of immune contexture on clinical outcome independently of the pathological stage in a large cohort of CRC specimens. ${ }^{12,83}$ Essentially, they found that the density of memory $\mathrm{CD}^{+} \mathrm{T}$ cells and memory $\mathrm{CD}^{+} \mathrm{T}$ cells in the core of CRC lesions was negatively correlated with tumor recurrence. In a following study, they established that the combined analysis of the expression of cytotoxic (IFNG, TAP1, and GZMB) and Th17 (IL17a and RORC)-related clusters of genes allows a better prediction of relapse. ${ }^{13}$ The 
detection of a Th17 cluster was associated with the expression of CCL24, but not CXCL9 or CXCL10.

In conclusion, IL-17 detection in the tumor site has a complex clinical significance. For that reason, its geographic localization in the neoplasm plus the concomitant characterization of functional markers including chemokines (CXCL9, CXCL10 versus CXCL1, CXCL5), receptors (eg, CCR4), cytokines (eg, IFN- $\gamma$ ), and lineage markers (eg, $\gamma \delta$-TCR or myeloid markers) might dramatically clarify and improve the prognostic value of IL-17.

\section{Therapeutic perspectives of Th 17 and IL-I7 in cancer}

It is only recently that we started to appreciate the functional diversity and plasticity of Th17 cells. The association of IL-17 and Th17 with a variety of chronic inflammatory disorders has led to the development of an increasing arsenal of inhibitors being tested in clinical trials to develop immunotherapies targeting the pathogenic IL-23/IL-17 axis. ${ }^{84,85}$ These trials have posted some success, especially in conditions such as psoriasis, ankylosing spondylitis, rheumatoid arthritis, and inflammatory bowel disease (IBD). ${ }^{86}$ However, no clinical trials specifically targeting IL-17 have yet been attempted as a treatment for cancer. As a result, therapeutic tools in the form of drugable blocking mAbs (humanized or fully human) or small-molecule inhibitors have flourished and are being interrogated for their clinical activity and toxicity profile (Phase I and II clinical trials; Table 2). Recent results of clinical trials in inflammatory disorders should be used as leverage to test these tools in cancer immunotherapy. Obviously, two radically opposed strategies should be applied according to the type of cancer and the clinical impact of IL-17 in tumor progression: 1) blocking deleterious IL-17-driven inflammation in cases where IL-17 is associated with poor prognosis; or 2) promoting antitumor Th17 response in cases where IL-17 is associated with good prognosis.

\section{Blocking IL-I7/Th I 7}

Different approaches could be exploited to block protumoral effects of IL-17 adopting results extrapolated from the inflammatory disease immunotherapy field. The first option relies on the use of mAb blocking IL-17 or IL-17R and IL-23; the second choice consists of using small-molecule inhibitors that target key molecules in the IL-17 pathway (eg, STAT3 or ROR).

\section{Pharmacological blocking of IL- 7 signaling (anti-ILI7 and anti-ILI7R mAbs)}

IL-17 and related cytokines have been successfully targeted for the treatment of autoimmunity. ${ }^{84} \mathrm{~A}$ variety of clinical trials focused on hindering the proinflammatory properties of IL-17 in autoimmune disorders including psoriasis, IBD, sclerosis, and even in allergies. Whereas blockade of IL-17 or IL-17R is effective in the therapy of psoriasis, so far little benefit has been observed in Crohn's disease. These discrepancies between inflammatory disorders emphasize how complex the pathogenic role of IL-17 and Th17 is. Of note, blockade of IL-17 and IL-23 signaling pathways was shown to significantly decrease the incidence of colon tumors in experimental models of colitis-associated cancer related to chronic inflammatory disorders, and where IL-17 has been proven to be responsible in the promotion of tumorigenesis. ${ }^{52,68}$ On these grounds, it is reasonable to postulate that even though blockade of IL-17 (with or without blockade of IL-23) did not improve colitis in humans, it may decrease the long-term pathogenic effects of IL-17 on the epithelium, therefore reducing the CRC incidence in this patient population. Furthermore, considering that the IL-17/Th17 pathway has been linked to poor prognosis in CRC patients, ${ }^{13}$ it could be anticipated that the detection of an IL-17 signature in cancer lesions could render patients eligible for adjuvant anti-IL-17 and/or IL-23 immunotherapies.

\section{Blocking ThI 7 differentiation}

Several protocols that could affect the Th17 polarization are already in place for the treatment of inflammatory disorders, like mAbs against IL-23 and IL-6R, or IL-1R antagonists and small-molecule inhibitors that target STAT3 (Table 2). Given that IL-23 promotes the expansion and survival of Th17, blocking the IL-23 pathway is one of the possibilities to directly impact the IL-17 response and tumor development. However, just like IL-17 and Th17, the role of IL-23 should be considered according to the context of the cancer of origin. While IL-23 deficient mice have been shown to be resistant to carcinogen-induced skin cancer, IL-23-transduced DCbased vaccine can lead to strong antitumor responses with increased $\mathrm{CD} 8^{+}$cytotoxic $\mathrm{T}$ cell recruitment. ${ }^{87,88} \mathrm{~A}$ Phase II clinical trial of therapies targeting IL-12/p40, common to IL-12 and IL-23, showed encouraging results in the treatment of psoriasis, but rendered individuals with an increased susceptibility to infections. ${ }^{84} \mathrm{~A}$ Phase III randomized controlled trial that used the fully human IL-12/IL-23 mAb (briakinumab) in moderate-to-severe psoriasis reported that briakinumab was paradoxically associated with an increased risk of cancer, including non-melanoma skin cancer, although this increase was not statistically significant and not clearly linked to a direct effect of IL-12/IL-23 or the use of adjuvant phototherapy. ${ }^{89}$ A potential explanation could be that the blockade of IL-12 decreased antitumor immunosurveillance 
(IFN- $\gamma$, TH1, and CTL), leading to an increased risk of developing skin tumors. Accordingly, the use of a more specific mAb such as MK-3222 (IL-23 and IL-19 inhibitor), which should spare the IL-12/IFN- $\gamma$ axis classically associated with antitumor response, appears more appropriate for the cancer immunotherapeutic approach. Anti-IL-6R mAb (tocilizumab) and IL-1Ra antagonist (anakinra) are also available in the clinical setting. However, despite being involved in Th17 polarization, IL-1 and IL-6 have been shown to be dispensable cytokines for effector Th17 cells.

Because the clinical impact of IL-17 detection in tumor is largely unknown, it is hard to predict whether blockade of IL-17 or inhibition of Th17 differentiation would bring any therapeutic benefit to patients, or if it would aggravate the disease. The use of these regimes would seem more applicable in reducing the incidence of cancer in patients already suffering from chronic inflammatory disorders (eg, IBD and CRC; dermatoses and skin cancers; pancreatitis and HCC). To our knowledge, the only listed cancer-related clinical trials targeting the IL-17 pathway are agents using the STAT3 inhibition route. Even though most of the trials listed in clinicaltrials. gov are not specifically targeting IL-17, these small-molecule inhibitors have been tested in numerous different types of hematopoietic-derived cancers and solid tumors. Admitting that most of these studies are incomplete, very limited benefits have been obtained. In certain clinical trials, like in the case of renal cell carcinoma (NCT00550277; a Phase II trial testing LBH589 for the treatment of patients with refractory clear cell renal carcinoma ${ }^{90}$ ), no promising results were observed and the recruitment of the study was stopped. It is, however, fair to note that the effects of such treatment on IL-17 or Th17 infiltration were not documented. Nevertheless, one clinical trial using histone deacetylase (HDAC) inhibitors in patients with cutaneous T cell lymphomas (CTCL) and benign dermatoses is monitoring Th17 in cancer lesions (NCT0166357191). HDAC inhibitors regulate STAT3 transcriptional activity and hence can potentially be active in CTCL through modulation of this proinflammatory pathway. The investigators will investigate whether HDAC inhibitors have a direct impact on the number of Th17 cells, the cytokine production by these cells, and phosphorylated STAT3 protein in CTCL with subsequent treatment cycles.

\section{Small-molecule inhibitors to oppose IL-I 7 production}

Inhibitors of Th17 lineage transcription factors ROR $\gamma t$ and ROR $\alpha$ have beneficial anti-inflammatory effects in experimental models of inflammatory disease. ${ }^{92}$ These agents hold promise to dim the protumoral effect of IL-17 in certain types of cancers in which the detection of IL-17 has been associated with bad outcomes. SR1001, a high-affinity synthetic ligand that is specific to both $\operatorname{ROR} \alpha$ and ROR $\gamma$ t and which inhibits Th17 cell differentiation and function, has been shown to inhibit sclerosis in animal models. ${ }^{93}$ Yet, attention should be paid to this drug due to its critical regulation in the hepatic metabolism. Vidofludimus (4SC-101) (NCT0082036594: Crohn's disease or ulcerative colitis [UC]; NCT01010581 ${ }^{95}$ : rheumatoid arthritis) is a potent inhibitor of human dihydroorotate dehydrogenase and of IL-17 secretion in vitro and in vivo. It was examined in several relevant animal models, showing beneficial effects in the case of acute colitis in mice with a coincidental decrement in IL-17A/A and A/F production. ${ }^{96}$ In fact, a Phase II trial in Crohn's disease using vidofludimus is being pursued as the next step. Tofacitinib (CP-690,550) inhibits JAK1, JAK3, STAT3, and IL-17 and it is being utilized in the treatment of rheumatoid arthritis, UC, and psoriasis. Despite the fact that both inhibitors have demonstrated a relatively good safety profile in clinical studies, the concern is that vidofludimus and tofacitinib also reduce IFN- $\gamma$ secretion, an effect which could be detrimental in the treatment of cancer. Much further optimization of these small-molecule inhibitors should therefore be performed in preclinical and clinical studies to avoid undesirable side effects.

\section{Interventions promoting IL- I 7/THI7}

\section{Adoptive transfer of THI 7 or Tcl 7}

In vitro polarized CD4 and CD8 T cells that produce IL-17 have been shown to have antitumor activity when adoptively transferred into tumor-bearing mice. ${ }^{47,48,53,97}$ However, whereas infusion of in vitro expanded $\mathrm{CD}^{+} \mathrm{T}$ cells in cancer patients has been intensively studied in clinical trials, there has been very little effort to use polarized $\mathrm{CD}^{+}{ }^{+}$cells (including Th17) in the clinic because of their functional instability rendering their therapeutic efficiency relatively uncertain..$^{98,99}$

\section{Inhibition of IDO and arginase}

Amino acid metabolism can profoundly affect immune cell function; two key amino acids in this respect are arginine and tryptophan. IDO metabolizes the essential amino acid L-tryptophan and arginase metabolizes arginine. High levels of either enzyme are associated with functional inhibition of T cells and other cell populations, such as DC. IDO overexpression is observed in a variety of human cancers and can be an independent adverse prognostic factor. ${ }^{100}$ IDO can also be induced in DC and macrophages in the TME by Treg cells. A specific small-molecule inhibitor of IDO, 1-methyl-tryptophan and a similar inhibitor for arginase, N-Methylarginine, are being studied preclinically 
and clinically. Sharma et al demonstrated that inhibition of IDO reprograms Treg toward Th17 in situ and increased CD8 ${ }^{+}$CTL. ${ }^{41}$ With this rationale, a combination of IDO-inhibitor drugs plus chemotherapy and perhaps immunotherapy could help block the reestablishment of suppressive activity by IDO in the tumor bed. Indoximod (1-methyl-D-tryptophan inhibitor) is currently being tested in refractory solid tumors including breast, lung, melanoma, and pancreatic malignancies (Phase I and II clinical trials). Alternatively, a study employing an IDO peptide vaccination in NSCLC patients was completed in a Phase I trial and results remain to be published (NCT01219348 ${ }^{101}$ ). Once again, these approaches are expected to be beneficial only in cancers in which Th17 detection is associated with a proper antitumor response and increased survival.

\section{Conclusion}

The therapeutic strategies targeting IL-17 in cancer remain in their infancy, but a plethora of drugs, mainly developed to block IL-17/Th17 in inflammatory disorders, are already in place for clinical development. ${ }^{84,92}$ However, mixed results of clinical trials aiming at inhibiting the Th17/IL-17 pathway in inflammatory diseases, predict that cancer patients should be carefully selected for IL-17-targeted therapy. The complexity of targeting Th17 for therapeutic purpose is indeed illustrated by the lack of improvement of Crohn's disease when blocking IL-17, which even led to deterioration of the disease in some clinical trials. It appears that epigenetic and transcriptional modifications dictated by the TME and specific to each cancer may account for the functional plasticity of infiltrating Th17, making it difficult to predict the role of this cell subset in tumor progression (protumor versus antitumor). Therefore, before targeting the IL-17 pathway to treat cancer, a better understanding of the mechanisms involved in IL-17 bioactivities during tumor development is required for each type of cancer.

Accordingly, the prognostic value of Th17 in cancer is highly heterogeneous and must be integrated to the immune "contexture." 12 A stratified selection of the patients based on the definition of multiple biomarkers and bioassays would help to improve clinical prognosis and personalize therapeutic decisions. Meanwhile, several recent studies reported that a polymorphism in $I l 17$, but not $I l 17 f$, genes may influence the susceptibility in cancer, including cervical, ${ }^{102}$ breast, ${ }^{103}$ and gastric. ${ }^{104,105}$ Though yet limited, such genetic link between IL-17 and cancers may allow future routine testing to better evaluate the risk of cancer and the therapeutic response.

\section{Disclosure}

The authors report no conflicts of interest in this work.

\section{References}

1. Hanahan D, Weinberg RA. Hallmarks of cancer: The next generation. Cell. 2011;144(5):646-674.

2. Pardoll DM. Cancer vaccines. Nat Med. 1998;4(Suppl 5):525-531.

3. Dranoff G. Immunotherapy at large: Balancing tumor immunity and inflammatory pathology. Nat Med. 2013;19(9):1100-1101.

4. Rosenberg SA, Yang JC, Restifo NP. Cancer immunotherapy: Moving beyond current vaccines. Nat Med. 2004;10(9):909-915.

5. van den Boorn JG, Hartmann G. Turning tumors into vaccines: co-opting the innate immune system. Immunity. 2013;39(1):27-37.

6. Motz GT, Coukos G. Deciphering and reversing tumor immune suppression. Immunity. 2013;39(1):61-73.

7. Pardoll DM. Spinning molecular immunology into successful immunotherapy. Nat Rev Immunol. 2002;2(4):227-238.

8. Pardoll DM. The blockade of immune checkpoints in cancer immunotherapy. Nat Rev Cancer. 2012;12(4):252-264.

9. Lipson EJ, Drake CG. Ipilimumab: An anti-CTLA-4 antibody for metastatic melanoma. Clin Cancer Res. 2011;17(22):6958-6962.

10. Pardoll DM. Immunology beats cancer: A blueprint for successful translation. Nat Immunol. 2012;13(12):1129-1132.

11. Topalian SL, Hodi FS, Brahmer JR, et al. Safety, activity, and immune correlates of anti-PD-1 antibody in cancer. NEngl J Med. 2012;366(26): 2443-2454.

12. Fridman WH, Pagès F, Sautès-Fridman C, Galon J. The immune contexture in human tumours: Impact on clinical outcome. Nat Rev Cancer. 2012;12(4):298-306.

13. Tosolini M, Kirilovsky A, Mlecnik B, et al. Clinical impact of different classes of infiltrating T cytotoxic and helper cells (Th1, th2, treg, th17) in patients with colorectal cancer. Cancer Res. 2011;71(4): 1263-1271.

14. Harrington LE, Hatton RD, Mangan PR, et al. Interleukin 17-producing CD4+ effector T cells develop via a lineage distinct from the $\mathrm{T}$ helper type 1 and 2 lineages. Nat Immunol. 2005;6(11):1123-1132.

15. Park H, Li Z, Yang XO, et al. A distinct lineage of CD4 T cells regulates tissue inflammation by producing interleukin 17. Nat Immunol. 2005;6(11):1133-1141.

16. O'Shea JJ, Paul WE. Mechanisms underlying lineage commitment and plasticity of helper CD4+ T cells. Science. 2010;327(5969): 1098-1102.

17. Muranski P, Restifo NP. Essentials of Th17 cell commitment and plasticity. Blood. 2013;121(13):2402-2414.

18. Ye J, Su X, Hsueh EC, et al. Human tumor-infiltrating Th17 cells have the capacity to differentiate into IFN-gamma+ and FOXP3+ T cells with potent suppressive function. Eur J Immunol. 2011;41(4):936-951.

19. Beriou G, Costantino CM, Ashley CW, et al. IL-17-producing human peripheral regulatory $\mathrm{T}$ cells retain suppressive function. Blood. 2009; 113(18):4240-4249.

20. McGeachy MJ, Bak-Jensen KS, Chen Y, et al. TGF-beta and IL-6 drive the production of IL-17 and IL-10 by T cells and restrain T(H)-17 cellmediated pathology. Nat Immunol. 2007;8(12):1390-1397.

21. Ghoreschi K, Laurence A, Yang XP, et al. Generation of pathogenic $\mathrm{T}(\mathrm{H}) 17$ cells in the absence of TGF-beta signalling. Nature. 2010; 467(7318):967-971.

22. Lee YK, Turner H, Maynard CL, et al. Late developmental plasticity in the T helper 17 lineage. Immunity. 2009;30(1):92-107.

23. Kirchberger S, Royston DJ, Boulard O, et al. Innate lymphoid cells sustain colon cancer through production of interleukin-22 in a mouse model. J Exp Med. 2013;210(5):917-931.

24. Petrella TM, Tozer R, Belanger K, et al. Interleukin-21 has activity in patients with metastatic melanoma: A phase II study. J Clin Oncol. 2012;30(27):3396-3401.

25. Tong $\mathrm{Z}$, Yang $\mathrm{XO}$, Yan $\mathrm{H}$, et al. A protective role by interleukin-17F in colon tumorigenesis. PLoS One. 2012;7(4):e34959.

26. Cua DJ, Tato CM. Innate IL-17-producing cells: The sentinels of the immune system. Nat Rev Immunol. 2010;10(7):479-489.

27. Chang SH, Dong C. Signaling of interleukin-17 family cytokines in immunity and inflammation. Cell Signal. 2011;23(7):1069-1075. 
28. Maloy KJ, Powrie F. Intestinal homeostasis and its breakdown in inflammatory bowel disease. Nature. 2011;474(7351):298-306.

29. Sutton CE, Lalor SJ, Sweeney CM, Brereton CF, Lavelle EC, Mills KH. Interleukin-1 and IL-23 induce innate IL-17 production from gammadelta T cells, amplifying Th17 responses and autoimmunity. Immunity. 2009;31(2):331-341.

30. Wang B, Li L, Liao Y, et al. Mast cells expressing interleukin 17 in the muscularis propria predict a favorable prognosis in esophageal squamous cell carcinoma. Cancer Immunol Immunother. 2013;62(10): 1575-1585.

31. Zhu X, Mulcahy LA, Mohammed RA, et al. IL-17 expression by breastcancer-associated macrophages: IL-17 promotes invasiveness of breast cancer cell lines. Breast Cancer Res. 2008;10(6):R95.

32. Lin AM, Rubin CJ, Khandpur R, et al. Mast cells and neutrophils release IL-17 through extracellular trap formation in psoriasis. J Immunol. 2011;187(1):490-500.

33. Miossec P, Korn T, Kuchroo VK. Interleukin-17 and type 17 helper T cells. N Engl J Med. 2009;361(9):888-898.

34. McGeachy MJ, Chen Y, Tato CM, et al. The interleukin 23 receptor is essential for the terminal differentiation of interleukin 17-producing effector T helper cells in vivo. Nat Immunol. 2009;10(3):314-324.

35. El-Behi M, Ciric B, Dai H, et al. The encephalitogenicity of $\mathrm{T}(\mathrm{H}) 17$ cells is dependent on IL-1- and IL-23-induced production of the cytokine GM-CSF. Nat Immunol. 2011;12(6):568-575.

36. Basu R, Hatton RD, Weaver CT. The Th17 family: Flexibility follows function. Immunol Rev. 2013;252(1):89-103.

37. Quintana FJ, Basso AS, Iglesias AH, et al. Control of T(reg) and $\mathrm{T}(\mathrm{H}) 17$ cell differentiation by the aryl hydrocarbon receptor. Nature. 2008;453(7191):65-71.

38. Huber M, Brüstle A, Reinhard K, et al. IRF4 is essential for IL-21mediated induction, amplification, and stabilization of the Th17 phenotype. Proc Natl Acad Sci U S A. 2008;105(52):20846-20851.

39. Yang XP, Ghoreschi K, Steward-Tharp SM, et al. Opposing regulation of the locus encoding IL-17 through direct, reciprocal actions of STAT3 and STAT5. Nat Immunol. 2011;12(3):247-254.

40. Dang EV, Barbi J, Yang HY, et al. Control of T(H)17/T(reg) balance by hypoxia-inducible factor 1. Cell. 2011;146(5):772-784.

41. Sharma MD, Hou DY, Liu Y, et al. Indoleamine 2,3-dioxygenase controls conversion of Foxp3+ tregs to TH17-like cells in tumordraining lymph nodes. Blood. 2009;113(24):6102-6111.

42. Pandiyan P, Conti HR, Zheng L, et al. CD4(+)CD25(+)Foxp3(+) regulatory $\mathrm{T}$ cells promote Th17 cells in vitro and enhance host resistance in mouse candida albicans Th17 cell infection model. Immunity. 2011;34(3):422-434.

43. Huber S, Gagliani N, Esplugues E, et al. Th17 cells express interleukin-10 receptor and are controlled by Foxp3 and Foxp3+ regulatory $\mathrm{CD} 4+\mathrm{T}$ cells in an interleukin-10-dependent manner. Immunity. 2011;34(4):554-565.

44. Chaudhry A, Rudra D, Treuting P, et al. CD4+ regulatory T cells control TH17 responses in a Stat3-dependent manner. Science. 2009;326(5955):986-991.

45. Godin-Ethier J, Hanafi LA, Piccirillo CA, Lapointe R. Indoleamine 2,3-dioxygenase expression in human cancers: clinical and immunologic perspectives. Clin Cancer Res. 2011;17(22):6985-6991.

46. Koenen HJ, Smeets RL, Vink PM, van Rijssen E, Boots AM, Joosten I. Human CD25highFoxp3pos regulatory T cells differentiate into IL-17producing cells. Blood. 2008;112(6):2340-2352.

47. Muranski P, Boni A, Antony PA, et al. Tumor-specific Th17-polarized cells eradicate large established melanoma. Blood. 2008;112(2):362-373.

48. Yen HR, Harris TJ, Wada S, et al. Tc17 CD8 T cells: Functional plasticity and subset diversity. J Immunol. 2009;183(11):7161-7168.

49. Melton AC, Bailey-Bucktrout SL, Travis MA, Fife BT, Bluestone JA, Sheppard D. Expression of $\alpha v \beta 8$ integrin on dendritic cells regulates Th17 cell development and experimental autoimmune encephalomyelitis in mice. J Clin Invest. 2010;120(12):4436-4444.

50. Kryczek I, Banerjee M, Cheng P, et al. Phenotype, distribution, generation, and functional and clinical relevance of Th17 cells in the human tumor environments. Blood. 2009;114(6):1141-1149.
51. Zielinski CE, Mele F, Aschenbrenner D, et al. Pathogen-induced human TH1 17 cells produce IFN- $\gamma$ or IL-10 and are regulated by IL- $1 \beta$. Nature. 2012:484(7395):514-518

52. Grivennikov SI, Wang K, Mucida D, et al. Adenoma-linked barrier defects and microbial products drive IL-23/IL-17-mediated tumour growth. Nature. 2012;491(7423):254-258.

53. Martin-Orozco N, Muranski P, Chung Y, et al. T helper 17 cells promote cytotoxic T cell activation in tumor immunity. Immunity. 2009;31(5): 787-798.

54. Wang L, Yi T, Zhang W, Pardoll DM, Yu H. IL-17 enhances tumor development in carcinogen-induced skin cancer. Cancer Res. 2010; 70(24):10112-10120.

55. Kryczek I, Wei S, Szeliga W, Vatan L, Zou W. Endogenous IL-17 contributes to reduced tumor growth and metastasis. Blood. 2009; 114(2):357-359.

56. Benchetrit F, Ciree A, Vives V, et al. Interleukin-17 inhibits tumor cell growth by means of a T-cell-dependent mechanism. Blood. 2002;99(6): 2114-2121.

57. Numasaki M, Fukushi J, Ono M, et al. Interleukin-17 promotes angiogenesis and tumor growth. Blood. 2003;101(7):2620-2627.

58. Tartour E, Fossiez F, Joyeux I, et al. Interleukin 17, a T-cell-derived cytokine, promotes tumorigenicity of human cervical tumors in nude mice. Cancer Res. 1999;59(15):3698-3704.

59. Yang XO, Chang SH, Park H, et al. Regulation of inflammatory responses by IL-17F. $J$ Exp Med. 2008;205(5):1063-1075.

60. Wang L, Yi T, Kortylewski M, Pardoll DM, Zeng D, Yu H. IL-17 can promote tumor growth through an IL-6-Stat3 signaling pathway. $J$ Exp Med. 2009;206(7):1457-1464.

61. Numasaki M, Watanabe M, Suzuki T, et al. IL-17 enhances the net angiogenic activity and in vivo growth of human non-small cell lung cancer in SCID mice through promoting CXCR-2-dependent angiogenesis. $J$ Immunol. 2005;175(9):6177-6189.

62. He D, Li H, Yusuf N, et al. IL-17 promotes tumor development through the induction of tumor promoting microenvironments at tumor sites and myeloid-derived suppressor cells. J Immunol. 2010;184(5): 2281-2288

63. Chung AS, Wu X, Zhuang G, et al. An interleukin-17-mediated paracrine network promotes tumor resistance to anti-angiogenic therapy. Nat Med. 2013;19(9):1114-1123.

64. Charles KA, Kulbe H, Soper R, et al. The tumor-promoting actions of TNF-alpha involve TNFR1 and IL-17 in ovarian cancer in mice and humans. J Clin Invest. 2009;119(10):3011-3023.

65. Lu L, Pan K, Zheng HX, et al. IL-17A promotes immune cell recruitment in human esophageal cancers and the infiltrating dendritic cells represent a positive prognostic marker for patient survival. J Immunother. 2013;36(8):451-458.

66. Wakita D, Sumida K, Iwakura Y, et al. Tumor-infiltrating IL-17producing gammadelta $\mathrm{T}$ cells support the progression of tumor by promoting angiogenesis. Eur J Immunol. 2010;40(7):1927-1937.

67. Berger H, Végran F, Chikh M, et al. SOCS3 transactivation by PPAR $\gamma$ prevents IL-17-driven cancer growth. Cancer Res. 2013;73(12): $3578-3590$.

68. Wu S, Rhee KJ, Albesiano E, et al. A human colonic commensal promotes colon tumorigenesis via activation of $\mathrm{T}$ helper type $17 \mathrm{~T}$ cell responses. Nat Med. 2009;15(9):1016-1022.

69. Acosta-Rodriguez EV, Napolitani G, Lanzavecchia A, Sallusto F. Interleukins 1 beta and 6 but not transforming growth factor-beta are essential for the differentiation of interleukin 17-producing human T helper cells. Nat Immunol. 2007;8(9):942-949.

70. Kato T, Furumoto H, Ogura T, et al. Expression of IL-17 mRNA in ovarian cancer. Biochem Biophys Res Commun. 2001;282(3):735-738.

71. Yamada Y, Saito H, Ikeguchi M. Prevalence and clinical relevance of Th17 cells in patients with gastric cancer. J Surg Res. 2012;178(2): 685-691.

72. Chen JG, Xia JC, Liang XT, et al. Intratumoral expression of IL-17 and its prognostic role in gastric adenocarcinoma patients. Int J Biol Sci. 2011;7(1):53-60. 
73. Lv L, Pan K, Li XD, et al. The accumulation and prognosis value of tumor infiltrating IL-17 producing cells in esophageal squamous cell carcinoma. PLoS One. 2011;6(3):e18219.

74. Ye ZJ, Zhou Q, Gu YY, et al. Generation and differentiation of IL-17producing CD4+ T cells in malignant pleural effusion. J Immunol. 2010;185(10):6348-6354.

75. Liu J, Duan Y, Cheng X, et al. IL-17 is associated with poor prognosis and promotes angiogenesis via stimulating VEGF production of cancer cells in colorectal carcinoma. Biochem Biophys Res Commun. 2011;407(2):348-354.

76. Lee JW, Wang $\mathrm{P}$, Kattah MG, et al. Differential regulation of chemokines by IL-17 in colonic epithelial cells. J Immunol. 2008;181(9):6536-6545.

77. Arenberg DA, White ES, Burdick MD, Strom SR, Strieter RM. Improved survival in tumor-bearing SCID mice treated with interferon-gammainducible protein 10 (IP-10/CXCL10). Cancer Immunol Immunother. 2001;50(10):533-538.

78. Mlecnik B, Tosolini M, Charoentong P, et al. Biomolecular network reconstruction identifies T-cell homing factors associated with survival in colorectal cancer. Gastroenterology. 2010;138(4):1429-1440.

79. Zhao Q, Xiao X, Wu Y, et al. Interleukin-17-educated monocytes suppress cytotoxic T-cell function through B7-H1 in hepatocellular carcinoma patients. Eur J Immunol. 2011;41(8):2314-2322.

80. Zhao F, Hoechst B, Gamrekelashvili J, et al. Human CCR4+ CCR6+ Th17 cells suppress autologous CD8+ T cell responses. J Immunol. 2012;188(12):6055-6062.

81. Zhang JP, Yan J, Xu J, et al. Increased intratumoral IL-17-producing cells correlate with poor survival in hepatocellular carcinoma patients. J Hepatol. 2009;50(5):980-989.

82. Vykhovanets EV, Maclennan GT, Vykhovanets OV, Gupta S. IL-17 expression by macrophages is associated with proliferative inflammatory atrophy lesions in prostate cancer patients. Int J Clin Exp Pathol. 2011;4(6):552-565.

83. Galon J, Costes A, Sanchez-Cabo F, et al. Type, density, and location of immune cells within human colorectal tumors predict clinical outcome. Science. 2006;313(5795):1960-1964.

84. Miossec P, Kolls JK. Targeting IL-17 and TH17 cells in chronic inflammation. Nat Rev Drug Discov. 2012;11(10):763-776.

85. Neurath MF. New targets for mucosal healing and therapy in inflammatory bowel diseases. Mucosal Immunol. Epub October 2, 2013.

86. Jones SA, Sutton CE, Cua D, Mills KH. Therapeutic potential of targeting IL-17. Nat Immunol. 2012;13(11):1022-1025.

87. Langowski JL, Zhang X, Wu L, et al. IL-23 promotes tumour incidence and growth. Nature. 2006;442(7101):461-465.

88. Overwijk WW, de Visser KE, Tirion FH, et al. Immunological and antitumor effects of IL-23 as a cancer vaccine adjuvant. J Immunol. 2006;176(9):5213-5222.

89. Langley RG, Papp K, Gottlieb AB, et al. Safety results from a pooled analysis of randomized, controlled phase II and III clinical trials and interim data from an open-label extension trial of the interleukin-12/23 monoclonal antibody, briakinumab, in moderate to severe psoriasis. J Eur Acad Dermatol Venereol. 2012;27(10):1252-1261.

90. SCRI Development Innovations, LLC. LBH589 Treatment for Refractory Clear Cell Renal Carcinoma. Available from: http://clinicaltrials. gov/show/NCT00550277. NLM identifier: NCT00550277. Accessed January 7, 2014.

91. New York University School of Medicine. STAT3 in T Cells: At The Crossroads of Inflammation and Cancer. Available from: http:// clinicaltrials.gov/show/NCT01663571. NLM identifier: NCT01663571. Accessed January 7, 2014.

92. Fitzpatrick LR. Inhibition of IL-17 as a pharmacological approach for IBD. Int Rev Immunol. 2013;32(5-6):544-555.
93. Solt LA, Kumar N, Nuhant P, et al. Suppression of TH17 differentiation and autoimmunity by a synthetic ROR ligand. Nature. 2011;472(7344): 491-494.

94. 4SC AG. SC12267 (4SC-101) for Treatment of Patients With Inflammatory Bowel Disease (ENTRANCE). Available from: http://clinicaltrials.gov/show/NCT00820365. NLM identifier: NCT00820365. Accessed January 7, 2014.

95. 4SC AG. SC12267 (4SC-101) in Combination With Methotrexate in Patients With Rheumatoid Arthritis (COMPONENT). Available from: http://clinicaltrials.gov/show/NCT01010581. NLM identifier: NCT01010581. Accessed January 7, 2014

96. Fitzpatrick LR, Deml L, Hofmann C, et al. 4SC-101, a novel immunosuppressive drug, inhibits IL-17 and attenuates colitis in two murine models of inflammatory bowel disease. Inflamm Bowel Dis. 2010;16(10):1763-1777.

97. Hinrichs CS, Kaiser A, Paulos CM, et al. Type 17 CD8+ T cells display enhanced antitumor immunity. Blood. 2009;114(3):596-599.

98. Zou W, Restifo NP. T(H)17 cells in tumour immunity and immunotherapy. Nat Rev Immunol. 2010;10(4):248-256.

99. Hinrichs CS, Gattinoni L, Restifo NP. Programming CD8+ T cells for effective immunotherapy. Curr Opin Immunol. 2006;18(3):363-370.

100. Uyttenhove C, Pilotte L, Théate I, et al. Evidence for a tumoral immune resistance mechanism based on tryptophan degradation by indoleamine 2,3-dioxygenase. Nat Med. 2003;9(10):1269-1274.

101. Inge Marie Svane. IDO Peptid Vaccination for Stage III-IV Non Small-cell Lung Cancer Patients. (IDOvaccine). Available from: http://clinicaltrials.gov/show/NCT01219348. NLM identifier: NCT01219348. Accessed January 7, 2014.

102. Quan Y, Zhou B, Wang Y, et al. Association between IL17 polymorphisms and risk of cervical cancer in chinese women. Clin Dev Immunol. 2012;2012:258293.

103. Wang L, Jiang Y, Zhang Y, et al. Association analysis of IL-17A and IL-17F polymorphisms in chinese han women with breast cancer. PLoS One. 2012;7(3):e34400.

104. Rafiei A, Hosseini V, Janbabai G, et al. Polymorphism in the interleukin-17A promoter contributes to gastric cancer. World $J$ Gastroenterol. 2013;19(34):5693-5699.

105. Arisawa T, Tahara T, Tsutsumi M, Shibata T. Influence of IL17A polymorphisms on the aberrant methylation of DAPK and CDH1 in non-cancerous gastric mucosa. BMC Med Genet. 2012;13:59.

106. Droeser RA, Güth U, Eppenberger-Castori S, et al. High IL-17-positive tumor immune cell infiltration is indicative for chemosensitivity of ovarian carcinoma. J Cancer Res Clin Oncol. 2013;139(8):1295-1302.

107. Chen WC, Lai YH, Chen HY, Guo HR, Su IJ, Chen HH. Interleukin-17-producing cell infiltration in the breast cancer tumour microenvironment is a poor prognostic factor. Histopathology. 2013;63(2):225-233.

108. Benevides L, Cardoso CR, Tiezzi DG, Marana HR, Andrade JM, Silva JS. Enrichment of regulatory $\mathrm{T}$ cells in invasive breast tumor correlates with the upregulation of IL-17A expression and invasiveness of the tumor. Eur J Immunol. 2013;43(6):1518-1528.

109. Chen X, Wan J, Liu J, et al. Increased IL-17-producing cells correlate with poor survival and lymphangiogenesis in NSCLC patients. Lung Cancer. 2010;69(3):348-354.

110. Li Q, Han Y, Fei G, Guo Z, Ren T, Liu Z. IL-17 promoted metastasis of non-small-cell lung cancer cells. Immunol Lett. 2012;148(2):144-150.

111. Zhang YL, Li J, Mo HY, et al. Different subsets of tumor infiltrating lymphocytes correlate with NPC progression in different ways. $\mathrm{Mol}$ Cancer. 2010;9:4.

112. Liao R, Sun J, Wu H, et al. High expression of IL-17 and IL-17RE associate with poor prognosis of hepatocellular carcinoma. J Exp Clin Cancer Res. 2013;32:3. 
ImmunoTargets and Therapy

Dovepress

\section{Publish your work in this journal}

ImmunoTargets and Therapy is an international, peer-reviewed open access journal focusing on the immunological basis of diseases, potential targets for immune based therapy and treatment protocols employed to improve patient management. Basic immunology and physiology of the immune system in health, and disease will be also covered. In addition, the journal will focus on the impact of manage-

ment programs and new therapeutic agents and protocols on patient perspectives such as quality of life, adherence and satisfaction. The manuscript management system is completely online and includes a very quick and fair peer-review system, which is all easy to use. Visit http://www.dovepress.com/testimonials.php to read real quotes from published authors.

Submit your manuscript here: http://www.dovepress.com/immunotargets-and-therapy-journal 